\title{
Que conhecimento explícito da área da fonética/fonologia trabalhar nos ensinos básico e secundário?
}

\author{
João Veloso \\ Faculdade de Letras da Universidade do Porto \\ Centro de Linguística da Universidade do Porto ${ }^{l}$
}

\begin{abstract}
:
In this text, we propose that formal, explicit teaching of very basic notions of phonetics and phonology is gradually introduced in the teaching of L1. The main arguments in favour of this point of view relate to the well-known beneficial effects of phonological awareness on the learning of writing and reading and to some educational experiences that have proven very effective in this field. We share the view that exposing students to the phonetic/phonological dimension of their own language throughout Basic and Secondary Education is doable and advisable so that a number of teachers and subjects benefit from this exposure: Biology, Philosophy, Literature, among others. A sequential, fixed order for the familiarisation of students with such notions is not presented here, as further research and educational experimentation is needed as to attain a reasonable consensos on this specific point.
\end{abstract}

Keywords: Explicit phonetic teaching; phonological awareness; literacy; L1 education

Palavras-chave: Treino fonético explícito; consciência fonológica; literacia; aprendizagem de L1

\section{Considerações introdutórias}

A investigação sobre a consciência fonológica em crianças em idade pré-escolar e nas primeiras fases da aprendizagem da leitura e da escrita conhece uma tradição longa e rica, que coloca ao nosso dispor dados tão importantes como a verificação de que a consciência fonológica detém uma função facilitadora relativamente a essas aprendizagens: estudos realizados e materiais desenvolvidos para aplicação em diversas línguas e em diferentes contextos nacionais e culturais revelam invariavelmente que crianças intensivamente expostas a tarefas precoces de desenvolvimento fonológico revelam menores dificuldades e maior rapidez no processo de aprendizagem da leitura e da escrita (Mark et al., 1977; Shankweiler et al., 1979; Fox \& Routh, 1980; Brady, Shankweiler \& Mann, 1983; Olofsson \& Lundberg, 1983; Lundberg, 1987: 473 e ss.; 1991: 52; Seymour, 1987; 1997; Wagner \& Torgesen, 1987; Bryant et al., 1989; Sim-Sim, 1989; 1997; Gombert, 1990:197; 1992; Goswami \& Bryant, 1990; Rebelo, 1990; Blachman, 1991; Shankweiler, 1991; Vellutino \& Scanlon, 1991; Mousty et al., 1994; Jiménez González \& Ortíz González, 1994; Coimbra, 1997; Lyster, 1997; Muter \& Snowling, 1997; Cielo, 1998; Cielo \& Poersch, 1998; Elbro, Borstrøm \& Petersen, 1998; Viana, 1998; Wood \& Terrell, 1998; Barbeiro, 1999; Martins, 2000; Durgunoğlu \& Öney, 2002; Hoover, 2002; Gillon, 2004; Yopp \& Yopp, 2009; Cardoso, Silva \& Pereira, 2013; Sari \& Aktan Acar, 2013; Sun, Zhou \& Zhu, 2013; Ferreira \& Veloso, 2014; LeRoux, 2016; Alcock, Ngorosho \& Jukes, 2018; Gonzales \& Tejero Hughes, 2018). Uma das consequências das principais conclusões partilhadas por estes estudos foi a adoção de posições oficiais, por parte de organismos governamentais e ordens profissionais ou organismos congéneres de diversos países, relativamente à integração do treino metafonológico precoce nos programas oficiais de ensino da leitura e da escrita (International Reading Association, 1998; Silva et al., 2011; CCEA, s/d).

${ }^{(1)}$ FCT - UID/LIN/0022/2016 
O objeto central de reflexão destas notas não se focaliza, porém, no domínio da consciência fonológica em si mesma, concebida como a capacidade de o sujeito refletir explicitamente sobre as propriedades fonéticas e fonológicas do material verbal, processando-o como uma combinação de entidades "opacas" e objetivamente observáveis conforme demonstrado, p. ex., através de um conjunto de capacidades de manipulação explícita de material verbal com base em critérios relacionados com as suas propriedades fonético-fonológicas. O objetivo deste trabalho não se encontra também no âmbito da relação que esse tipo de competências estabelece com o processo de aprendizagem da leitura e da escrita. Nos parágrafos que se seguem, centraremos a nossa atenção numa questão que, embora se relacione com as questões colocadas nesse nível linguístico e cognitivo, se situa num plano diferenciado: debruçar-nos-emos sobre a questão dos conhecimentos explícitos de fonética e de fonologia que, ao longo da aprendizagem formal da língua materna, podem - ou devem - ser objeto de atividades orientadas, integrando o corpus de conhecimentos e noções explícitas objetivamente transmitidas aos estudantes (incluindo a sua familiarização terminológica com alguns conceitos básicos desta área da descrição estrutural da língua) e fazendo parte dos objetivos mínimos a atingir em dados marcos temporais do percurso escolar. Tentaremos pôr em evidência que, além do interesse intrínseco do trabalho escolar sobre estas questões, o seu estudo pode ter um impacto positivo na exploração de outras áreas, como a análise do texto literário, a prevenção dos erros ortográficos e a expressão oral, entre outros.

Também a este nível, a produção científica tem colocado à nossa disposição materiais diversos que defendem a inclusão precoce de conhecimentos explícitos de fonética e fonologia desde os primeiros anos de escolaridade, em grande medida com base nos argumentos sumariados na parte final do parágrafo anterior. No que diz respeito ao português, citaremos, nesta contextualização da questão, estudos como, p. ex., os de Duarte (2000), Freitas \& Santos (2001), Veloso \& A. Rodrigues (2002), S. Rodrigues (2006), Veloso (2006), Freitas, Alves \& Costa (2007), Duarte et al. (2011), Gonçalves, Guerreiro \& Freitas (2011), Silva et al. (2011) ou Freitas et al. (2012).

As recentes redefinições de conteúdos curriculares e aprendizagens essenciais em língua materna têm, em graus diferentes, concedido algum destaque às questões de fonética e fonologia, pelo que todas as reflexões e discussões dos temas relacionados com o grande eixo temático que lhes subjaz nos parecem justificadas. Neste texto, independentemente de considerações teóricas mais ou menos desenvolvidas sobre o ensino da língua materna e independentemente também das diversas revisões de carácter curricular no ensino da língua portuguesa nos níveis básico e secundário concretizadas nos últimos anos, tentaremos inventariar um conjunto de conhecimentos, competências e noções básicas nestes domínios que deveriam ser trabalhados nos 12 anos de escolaridade obrigatória, tentando justificar a sua inserção nesta lista ou conjunto de conhecimentos e competências. A principal orientação que guiará as escolhas e propostas vertidas para este texto radica na formação linguística do autor e no seu envolvimento em atividades de formação de professores de Português o que, podendo trazer algumas fragilidades metodológicas a algumas das propostas aqui apresentadas, poderá também proporcionar um olhar menos comprometido com a discussão metodológica e dos aspetos mais formais das revisões curriculares em si, cuja importância é aqui plenamente reconhecida e cujo cruzamento com uma discussão mais "científica" dos conteúdos a trabalhar se torna inevitável, mas que não será objeto aprofundado destas notas. A ordem pela qual os diversos conceitos de fonética e fonologia considerados desta forma "imprescindíveis" no ensino formal do português como língua materna na escolaridade básica e secundária serão aqui mencionados não reflete a ordem pela qual tais conceitos devem ser apresentados ao longo desse percurso escolar. Esta questão foi deliberadamente deixada de lado neste estudo, pois cremos que ela deverá consubstanciar-se em decisões normativas ancoradas numa reflexão mais alargada, que envolva inclusivamente a problematização dos conteúdos de outras disciplinas, bem como em projetos-piloto, trabalhos de campo, experiências educativas e outras fontes de investigação e investigação-ação que não foram aprofundadamente consideradas na elaboração destas notas. 


\section{Conteúdos a transmitir e avaliar explicitamente nos domínios da fonética e da fonologia do português ao longo dos 12 anos da escolaridade}

Como afirmámos nas notas introdutórias deste artigo, a nossa proposta central, neste estudo, é traçar um conjunto de conteúdos fonético-fonológicos que deveriam ser objeto de trabalho explícito na aula de Português (língua materna) ao longo dos 12 anos de escolaridade básica e secundária. É nosso objetivo deliberado afastarmo-nos de questões de natureza mais prática ou procedimental como a via metodológica mais apropriada para se trabalharem as diversas questões, bem como a ordem e os momentos em que poderá e deverá dar-se a aproximação a esses conteúdos. Conforme afirmámos, interessa-nos sobretudo concentrarmo-nos na contribuição para uma discussão que um dia conduza a um consenso sobre os conteúdos a trabalhar, apresentando para esses conteúdos as razões que nos levam a propor a sua inclusão nessa "lista consensual".

Dividiremos a apresentação da proposta de conteúdos em

- conteúdos transversais: conhecimentos que poderão ser trabalhados em diversas áreas;

- conteúdos gramaticais: conhecimentos que deverão ser trabalhados em momentos específicos da aula consagrados ao trabalho explícito sobre as estruturas e o funcionamento da língua;

- conteúdos aplicados: conhecimentos que, trabalhados sobretudo na aula de Português eventualmente, em aulas de outras disciplinas de língua também -, podem ter lugar na aproximação a conteúdos não estritamente gramaticais.

A lista de conteúdos que passaremos a apresentar não é exaustiva; como já afirmámos, pretende ser um contributo a confrontar com outros. Para a sua elaboração, adotámos fundamentalmente o ponto de vista de um linguista com intervenção na investigação e no ensino superior destas matérias e que, com base nessa experiência pessoal e académica, propõe aqui um "filtro" de noções, conhecimentos e capacidades consideradas essenciais e imprescindíveis no final do percurso da escolaridade secundária em Portugal. Não houve, portanto, por trás da escolha destas e não de outras noções critérios muito objetivos, estudos empíricos, inquéritos ou comparação com experiências internacionais neste domínio; a nossa preocupação foi guiada por uma avaliação um tanto subjetiva da urgência e do carácter fundamental destas aprendizagens e pela leitura de estudos anteriores sobre estas matérias, como os citados na secção 1 do artigo.

\subsection{Conteúdos transversais}

Chamamos conteúdos transversais aos conteúdos de fonética e fonologia que podem ser abordados na aula de Português mas que o podem ser igualmente no âmbito de trabalho noutras disciplinas. Trata-se, a nosso ver, de uma forma de promover a interdisciplinaridade e a flexibilização curricular, potenciando o trabalho conjunto entre áreas e promovendo a ideia de que o contributo da linguística para a disciplina de Português não se confina exclusivamente ao chamado "saber humanístico" nem às ligações com a literatura ou a história, p. ex.

O primeiro conteúdo que, neste contexto, ocorre aqui mencionar é a descrição do aparelho fonador humano. A identificação dos órgãos responsáveis pela produção/realização dos diversos fonemas da língua para, a partir daí, se atingir uma classificação "articulatória" dos sons corresponde a um dos objetivos primordiais da fonética. Noutra secção, proporemos que o conhecimento da taxonomia das unidades fonémicas da língua deve ser também um conteúdo a trabalhar na aula de Português. Um conhecimento mais informado das estruturas anatómicas que intervêm na produção da fala ajudará o aluno a:

- ampliar o conhecimento do seu próprio eu físico;

- conceber a língua e a linguagem como realidades também determinadas por variáveis de ordem biológica e fisiológica, universais na medida em que partilhadas por todos os seres da espécie;

- situar a linguagem no processo de hominização, percebendo a especialização evolutiva que certas estruturas anatómicas sofreram devido ao desenvolvimento da linguagem na espécie humana; 
- evitar, no momento da aprendizagem da classificação articulatória dos fonemas da língua, a memorização pura e simples de etiquetas terminológicas de certa forma desprovidas de um conteúdo mais estruturado;

- aperceber-se proprioceptivamente de como o seu aparelho fonador atua na produção dos sons;

- perceber melhor a divisão dos sons presentes nas realizações fonéticas de todas as línguas estudadas em grandes famílias, conduzindo-o a divisões de âmbito mais geral e, simultaneamente, mais fundamental, como consoante/vogal, surdo/sonoro, oral/nasal, etc.

Por outro lado, a exploração destes conteúdos constitui uma oportunidade muito óbvia e determinada de trabalho conjunto com os professores e as disciplinas das áreas mais relacionadas com a Biologia ou, querendo levar mais longe esta interdisciplinaridade, as Artes Plásticas, na representação visual das estruturas anatómicas usadas na fala, ou a Filosofia, na discussão da dualidade mente/corpo, da dimensão universal de certas propriedades humanas e nas implicações éticas dessa universalidade.

Neste âmbito, parece-nos justificado que, no final do $12^{\circ}$ ano de escolaridade, qualquer estudante esteja na posse de uma quantidade de conhecimentos essenciais acerca de aspetos como os seguintes:

- Configuração geral do aparelho fonador e a sua divisão em três regiões principais: cavidades infraglógicas, cavidade glótica e cavidades supraglóticas;

- A interação entre respiração, deglutição e fonação;

- O papel das cordas vocais na distinção entre sons vozeados e não vozeados;

- O papel do véu palatino na distinção entre sons orais e nasais;

- O papel da cavidade oral na distinção entre:

- contoides e vocoides ("consoantes" vs. "vogais"),

- sons labiais, dentais, dorsais/palatais e velares; altos e baixos; abertos e fechados;

arredondados e não arredondados.

\subsection{Conteúdos gramaticais}

Entramos agora numa apresentação daqueles conteúdos intrinsecamente fonéticos e/ou fonológicos e que, de acordo com a proposta aqui esboçada, teriam melhor cabimento em momentos letivos especificamente dedicados ao ensino da gramática - das estruturas e das formas da língua e do seu funcionamento.

Como recordado em Veloso \& A. Rodrigues (2002), Rodrigues (2006) ou Veloso (2006) - e como, a propósito do ensino das línguas estrangeiras em geral nos é frequentemente sublinhado por Champagne-Muzar \& Bourdages (1998), entre outros -, a componente fonológica da língua:

(i) é parte integrante da sua gramática, ou seja, do conjunto de regras que presidem à boa formação de todos os produtos verbais;

(ii) não obstante, é porventura a componente gramatical-estrutural das línguas mais negligenciada na prática pedagógica, sendo comummente concebida como uma componente secundária e "tributária da escrita”, na expressão de Champagne-Muzar \& Bourdages (1998: 3).

Tal como sublinhámos em Veloso (2006), a aprovação da TLEBS em 2004 marca um certo momento de viragem, no ensino do português como língua materna, relativamente a esse estado de coisas, ao ampliar consideravelmente o corpus de noções fonético-fonológicas que deveriam compor a terminologia de trabalho mínima de um professor de Português dos Ensinos Básico e Secundário. As reformas curriculares do ensino de Português a partir de 2009 pelo menos, com um fortalecimento da vertente da expressão oral - fortemente ancorada num domínio implícito e explícito de um conjunto de noções articulatórias, fonológicas e prosódicas (Silva et al., 2011) - vieram consolidar essa tendência, justificando, em nosso entendimento, que se estabeleça uma lista de noções e conceitos que deveriam integrar um conjunto não necessariamente muito alargado mas 
suficientemente desenvolvido e coeso de noções fonéticas que fossem do conhecimento explícito dos estudantes no final do $12^{\circ}$ ano de escolaridade.

De tais noções deveriam fazer parte, pelo menos, as que passamos a expor.

A primeira grande noção a trabalhar, de modo transversal a todos os conhecimentos aqui contemplados, em diversos momentos e com suficiente insistência, deveria focar-se na divisão entre a representação gráfica da língua e a sua representação sonora. Sendo certo que, em português, as representações escritas e as realizações fonéticas estabelecem entre si uma relação minimamente estável e regular, não é infrequente encontrarmos estudantes, mesmo no nível superior, ou mesmo materiais didáticos, que proferem afirmações muitas vezes baseadas numa confusão muito fácil de evitar entre o universo escrito e o universo oral e as suas unidades segmentais mínimas, como, recorrendo à terminologia mais tradicional e corrente neste domínio, o fonema e o grafema. Insistir em exercícios e atividades preparatórias que levem os alunos a compreender que $\mathrm{o}<\mathrm{h}>$ inicial de palavras como hoje e homem não passa de uma convenção etimologicamente motivada, sem qualquer correspondência na forma fonética contemporânea destas palavras em português, ou que demonstrem que o dígrafo <ch> de chave corresponde a um só fonema ou, finalmente, que a translineação <car//ro>, também convencional, não tem correspondência com a divisão silábica [ $\forall \kappa \alpha . \geq U]$ são meros exemplos desta consciencialização que despertará nos alunos uma consciência mais explícita do nível fonológico e do seu lugar na arquitetura do sistema linguístico.

Olhando a níveis mais pormenorizados, uma parte importante do trabalho a desenvolver consistirá na interiorização de algumas unidades fundamentais do nível fonético e fonológico, das suas propriedades e do seu funcionamento. Entre tais unidades, as mais fundamentais e, por conseguinte, mais imprescindíveis nesta dimensão de atuação deveriam contemplar pelo menos as seguintes, bem como algumas noções secundárias associadas relativas a unidades e processos, em termos parecidos com os que passamos a enumerar:

- o fonema, como unidade segmental, sucessiva e mínima, basicamente coincidente com uma consoante ou uma vogal no nível das unidades fonéticas empiricamente acessíveis, e dotado de função distintiva - o que tornaria necessário, também, alguma consciencialização do par mínimo (a par da distinção entre plano fónico e plano gráfico);

- a sílaba, como unidade combinatória básica e como unidade que recebe o acento tónico da palavra, responsável, por um lado, pela distinção entre sílabas tónicas e sílabas átonas e, por outro, pela divisão tradicional entre palavras monossilábicas e polissilábicas (quanto ao número de sílabas) e entre palavras agudas/oxítonas, graves/paroxítonas e esdrúxulas/proparoxítonas (quanto à posição do acento).

Ainda no campo da exploração das questões fonético-fonológicas a partir de uma perspetiva predominantemente descritiva/estrutural/gramatical, caberiam, nos momentos e pelas vias metodológicas julgadas apropriadas, reflexões acerca de aspetos como os seguintes:

- o acento como proeminência prosódica dentro da palavra, com diferenciação entre acento primário ou tónico (na maioria das palavras simples) e acento secundário, em palavras morfologicamente mais complexas como os compostos morfossintáticos, os advérbios em -mente e os nomes formados com sufixo z-avaliativo. Ainda a propósito do trabalho sobre o acento, caberia uma reflexão sobre as palavras e formas clíticas, no âmbito do qual seria possível demonstrar - no caso das formas átonas do pronome pessoal - a ligação da fonologia à morfologia e abordar a variação linguística do português (com referência às diferenças na ordem dos clíticos verificadas nas variedades brasileira e africanas da língua);

- a redução do vocalismo átono como um processo idiossincrático do português europeu contemporâneo, o que, por sua vez, poderia propiciar alguma reflexão sobre os fenómenos de variação linguística, mais concretamente sobre as variedades do português extra-europeu, que fazem atualmente parte dos programas de Português e permitem a aproximação em aula a temas como o multiculturalismo, a globalização e a história da expansão marítima de Portugal, tópicos trabalhados em Português e noutras disciplinas; 
- algumas distinções básicas (algumas contempladas no âmbito do trabalho de apresentação do aparelho fonador), como consoante $\neq$ vogal (permitindo o retomar da diferença entre plano fónico e plano gráfico), oral $\neq$ nasal, vozeado $\neq$ ão vozeado, ditongo fhiato, oclusivo/fricativo/nasal/vibrante/lateral e referência aos principais pontos de articulação consonântica da língua.

\subsection{Conteúdos aplicados}

Agrupamos nesta secção final do ponto 2 do texto aqueles conhecimentos que, tal como referimos em 1, constituem conhecimentos e conteúdos de natureza fonética e fonológica mas que podem ser trabalhados na aula de Português a partir da abordagem a outros tópicos, pertencentes a outros domínios e subdomínios.

Tal como se viu sobretudo na secção anterior, qualquer conteúdo ocorre sempre rodeado de outros conteúdos e, com esta proposta mais de tipo enumerativo (o que é condicionado principalmente pelas condições e pelo contexto em que o texto é apresentado), não é nosso objetivo sugerir sequer que as diferentes noções sejam apresentadas de forma sequencial, sem qualquer interligação ou contextualização de conjunto. Os conteúdos contemplados nesta secção, contudo, são aqueles que decorrem do trabalho noutros domínios e não, num primeiro momento, de um trabalho explicitamente direcionados para a sua apresentação sistemática em primeiro plano.

Neste campo, a presente proposta inclui:

- a distinção entre rima silábica e rima poética, que se oferece a ser trabalhada na exploração do texto poético versificado, aquando da apresentação dos vários tipos de verso, da escansão e das estruturas rítmicas do texto poético; entre outras virtualidades, uma abordagem como a aqui preconizada permitiria a menção aos fenómenos de ressilabificação e sândi, motivados pela inserção pós-lexical de palavras em contexto frásico;

- os recursos fono-estilísticos como uma parte fulcral dos recursos de enriquecimento literário e expressivo da linguagem, conforme patente no texto poético e no texto literário em geral, bem como noutras modalidades de texto em que a dimensão estética ou a "linguagem-enquanto-objeto-em-si-mesma" são variáveis que condicionam a produção e a receção desses produtos linguísticos;

- os mecanismos prosódicos de marcação de foco, tipo frásico e desambiguação, que poderia ter lugar a par da exploração sintática e pragmática de tópicos como as ambiguidades lexicais e estruturais, os tipos de frase (com insistência, uma vez mais, na diferença entre realização fonética e marcação gráfica) e estratégias de topicalização.

Em domínios como o desenvolvimento da expressão oral - conforme referido, uma valência do ensino da língua que foi conquistando, nos últimos anos, uma ponderação crescente no ensino da língua - e da análise formal e estilística dos textos literários, torna-se inevitável, para um ensino bem sucedido, fazer referência explícita às propriedades fonéticas e fonológicas que estão na origem, p. ex., da elocução e articulação cuidada ou dos já mencionados recursos fono-estilísticos (rima, aliteração, esquemas rimáticos, tipos de verso e de estrofe, cesura, etc.). Estamos perante domínios em que o recurso a alguma metalinguagem - e, mais do que isso, a uma certa conceptologia - relacionada com noções fonético-fonológicas básicas (como transmitir os conceitos de aliteração e assonância sem uma clara compreensão prévia das noções de consoante e vogal independente da sua expressão escrita, que pode ser enganadora em exemplos como "gestos, gastos e guerras"?) se torna um facilitador para a transmissão dos conceitos não intrinsecamente fonéticos a trabalhar. 


\section{Observações finais}

Ao longo das secções anteriores do texto, procurámos reunir um conjunto de argumentos que mostram que a exposição explícita e sistemática dos estudantes de Português (língua materna) ao longo do seu percurso na escoloaridade pré-universitária é não só possível como apresenta vantagens de diversa ordem:

- permite consolidar o conhecimento explícito dos estudantes sobre uma dimensão da sua própria língua muitas vezes negligenciada pelas práticas pedagógicas;

- potencia um diálogo entre a disciplina de Português e outras (como a Biologia, a História, a Filosofia, p. ex.) e, dentro da aula de Português, entre domínios como a (orto)grafia, a variação linguística e a análise do texto literário;

- desenvolvendo uma consciência clara da separação entre um nível gráfico e um nível fonéticofonológico, poderá conduzir os estudantes a uma atenção especial ao domínio gráfico, com consequências positivas a nível da prevenção do erro ortográfico (em linha com os estudos clássicos, citados na primeira parte do artigo, sobre o papel preditor da consciência fonológica sobre a aprendizagem da leitura e da escrita).

Deliberadamente, excluímos dos propósitos deste pequeno estudo uma proposta mais explícita do ritmo e da ordem por que as noções fonético-fonológicas poderiam ou deveriam ser introduzidas no percurso escolar dos alunos. Privilegiámos, em lugar dessa possível "sequencialização", a identificação de um conjunto mínimo de um corpus central de conhecimentos, noções e conceitos que, uma vez consensualizados a partir de uma reflexão mais alargada ${ }^{2}$, poderiam ter lugar ao longo dos 12 anos da escolaridade obrigatória de forma equilibrada, ponderada e integrada com conhecimentos transmitidos num leque mais vasto de disciplinas escolares.

\section{Referências}

Alcock, K. J.; Ngorosho, D. S.; Jukes, M. C. H. (2018) Reading and Phonological Awareness in Africa. Ms., Lancaster University.

Barbeiro, L. F. (1999) Os Alunos e a Expressão Escrita. Consciência Metalinguística e Expressão Escrita. Lisboa: Fundação Calouste Gulbenkian.

Blachman, B. A. (1991) Phonological Awareness: Implications for Prereading and Early Reading Instruction. In. S. A. Brady, D. P. Shankweiler (Eds.) Phonological Processes in Literacy. A Tribute to Isabelle Y. Liberman. Hillsdale (NJ): Lawrence Erlbaum, pp. 29-36.

Brady, S.; Shankweiler, D.; Mann, V. (1983) Speech Perception and Memory Coding in Relation to Reading Ability. Journal of Experimental Child Psychology 35, pp. 345-367.

Bryant, P. E.; Bradley, L.; MacLean, M.; Crossland, J. (1989) Nursery rhymes, phonological skills and reading. Journal of Child Language 16(2), pp. 407-428.

Cardoso, A. M. S.; Silva, M. M.; Pereira, M. M. B. (2013) Phonological awareness and the working memory of children with and without literacy difficulties CoDAS 25(2), pp. 110-114.

CCEA (s/d) Phonological Awareness. Belfast: Council for the Curriculum, Examinations and Assessment.

Champagne-Muzar, C.; Bourdages, J. S. (1998) Le point sur la phonétique. Anjou (Québec)/Paris: CLE International.

Cielo, C. A. (1998) A sensibilidade fonológica e o início da aprendizagem da leitura. Letras de Hoje 33(4), pp. 21-60.

Cielo, C. A.; Poersch, J. M. (1998) Relação entre a sensibilidade fonológica e o aprendizado inicial da leitura. Letras de Hoje 33(2), pp. 99-105.

\footnotetext{
${ }^{2}$ Dessa consensualização que é considerada desejável neste contexto pode, naturalmente, resultar uma ampliação, uma redução ou uma reformulação dos conteúdos fonéticos que são inventariados como os mínimos neste mesmo estudo.
} 
Coimbra, M. (1997) A habilidade metafonológica em crianças de cinco anos. Letras de Hoje 32(4), pp. 61-79. Duarte, I. (2000) Língua Portuguesa. Instrumentos de Análise. Lisboa: Universidade Aberta.

Duarte, I.; Colaço, M.; Freitas, M. J.; Gonçalves, A. (2011) O Conhecimento da Língua: Desenvolver a Consciência Lexical. Lisboa: Ministério da Educação/DGIDC.

Durgunoğlu, A. Y.; Öney, B. (2002) Phonological Awareness in Literacy Acquisition. It's Not Only for Children. Scientific Studies of Reading 6(3), pp. 245-266.

Elbro, C.; Borstrøm, I.; Petersen, D. K. (1998) Predicting dyslexia from kindergarten: The importance of distinctness of phonological representations of lexical items Reading Research Quarterly 33(1), pp. 36-60.

Ferreira, S.; Veloso, J. (2014) Efeito da estimulação em consciência fonológica no desempenho de crianças préescolares e o seu impacto sobre a leitura de palavras no $1^{\circ}$ ciclo do ensino básico. Revista Portuguesa de Terapia da Fala 1, pp. 5-12.

Fox, B.; Routh, D. K. (1980) Phonemic Analysis and Severe Reading Disability in Children. Journal of Psycholinguistic Research 9(2), pp. 115-119.

Freitas, M. J.; Alves, D.; Costa, T. (2007) O Conhecimento da Língua: Desenvolver a Consciência Fonológica. Lisboa: Ministério da Educação/DGIDC.

Freitas, M. J.; Rodrigues, C.; Costa, T.; Castelo, A. (2012) Os Sons que estão dentro das Palavras. Descrição e Implicações para o Ensino do Português como Língua Materna. Lisboa: Colibri/APP.

Freitas, M. J.; Santos, A. L. (2001). Contar (histórias de) Sílabas. Descrição e Implicações para o Ensino do Português como Língua Materna. Lisboa: Colibri/APP.

Gillon, G. T. (2004) Phonological Awareness. From Research To Practice. New York (NY): Guilford Press.

Gombert, J. E. (1990) Le développement métalinguistique. Paris: Presses Universitaires de France.

Gombert, J. E. (1992) Le rôle des capacités métaphonologiques dans l'apprentissage de la lecture. In. A. Bentolila (Ed.) Les entretiens Nathan. Actes II: Lecture et écriture. Paris: Nathan, pp. 55-62.

Gonçalves, F., Guerreiro, P.; Freitas, M. J. (2011) O Conhecimento da Língua: Percursos de Desenvolvimento. Lisboa: Ministério da Educação/DGIDC.

Gonzales, W.; Tejero Hughes, M. T. (2018) Libros en Mano: Phonological Awareness Intervention in Children's Native Languages. Education Sciences 8, pp. 1-12.

Goswami, U.; Bryant, P. (1990) Phonological Skills and Learning to Read. Hove: Lawrence Erlbaum.

Hoover, W. A. (2002) The Importance of Phonemic Awareness in Learning to Read. SEDL Letter XIV(3).

International Reading Association (1998) Phonemic Awareness and the Teaching of Reading. A Position Statement from the Board of Directors of the International Reading Association. Newark (DE): International Reading Association.

Jiménez González, J.; Ortíz González, M. R. (1994) Phonological Awareness in Learning Literacy. Intellectica 18 , pp. 155-181.

Le Roux, S. G. (2016) The role of family literacy programmes to support emergent literacy in young learners. $\mathrm{PhD}$ dissertation, UNISA.

Lundberg, I. (1987) Are Letters Necessary for the Development of Phonemic Awareness?. Cahiers de Psychologie Cognitive/European Bulletin of Cognitive Psychology 7(5), pp. 472-475.

Lundberg, I. (1991) Phonemic Awareness Can Be Developed Without Reading Instruction. In. S. A. Brady, D. P. Shankweiler (Eds.). Phonological Processes in Literacy. A Tribute to Isabelle Y. Liberman. Hillsdale (NJ): Lawrence Erlbaum, pp. 47-53.

Lyster, S.-A. (1997) Spelling Development and Metalinguistic Training Before School Entrance: The Effects of Different Metalinguistic Training on Spelling Development in First Grade. In. C. K. Leong, R. Malatesha Joshi (Eds.) Cross-Language Studies of Learning to Read and Spell. Phonologic and Orthographic Processing. Dordrecht: Kluwer/NATO, pp. 305-330. 
Mark, L. S.; Shankweiler D.; Liberman, I. Y.; Fowler, C. A. (1977) Phonetic recoding and reading difficulty in beginning readers. Memory and Cognition 5(6), pp. 623-629.

Martins, M. A. 2000. Pré-História da Aprendizagem da Leitura. Conhecimentos Precoces sobre a Funcionalidade da Linguagem Escrita, Desenvolvimento Metalinguístico e Resultados em Leitura no final do $1^{o}$ ano de Escolaridade. $2^{\mathrm{a}}$ ed. Lisboa: Instituto Superior de Psicologia Aplicada.

Mousty, P.; Leybaert, J.; Alégria, J.; Content, A.; Morais, J. (1994) BELEC - Une batterie d'évaluation du langage écrit et de ses troubles. In. J. Grégoire, B. Piérart (Eds.). Evaluer les troubles de la lecture. Les nouveaux modèles théoriques et leurs implications diagnosthiques. Paris/Bruxelles: De Boeck Université, pp. 127-145.

Muter, V.; Snowling, M. (1997) Grammar and phonology predict spelling in middle childhood. Reading and Writing 9, pp. 407-425.

Olofsson, A.; Lundberg, I. (1983) Can phonemic awareness be trained in kindergarten?. Scandinavian Journal of Psychology 24, pp. 35-44.

Rebelo, D. (1990) Estudo Psicolinguístico da Aprendizagem da Leitura e da Escrita. Lisboa: Fundação Calouste Gulbenkian.

Rodrigues, S. V. (2006) Fonética e fonologia no ensino da língua materna: Modos de operacionalização. In. I. Duarte, O. Figueiredo (Eds.). Terminologia Linguística: das teorias às práticas. Porto: Faculdade de Letras da Universidade do Porto, pp. 129-161

Sari, B.; Aktan Acar, E. (2013) The Phonological Awareness Scale of Early Childhood Period (PASECP) Development and Psychometric Features. Educational Sciences: Theory \& Practice 13(4), pp. 2209-2215.

Seymour, P. H. K. (1987) How Might Phonemic Segmentation Help Reading Development?. Cahiers de Psychologie Cognitive/European Bulletin of Cognitive Psychology 7(5), pp. 504-508.

Seymour, P. H. K. (1997) Foundations of Orthographic Development. In. C. A. Perfetti, L. Rieben, M. Fayol (Eds.) Learning to Spell. Research, Theory, and Practice Across Languages. Mawhaw (NJ): Lawrence Erlbaum, pp. 319-337.

Shankweiler D.; Liberman, I. Y.; Mark, L. S.; Fowler, C. A.; Fischer, F. (1979) The Speech Code and Learning to Read. Journal of Experimental Psychology: Human Learning and Memory 5(6), pp. 531-545.

Shankweiler, D. (1991) The Contribution of Isabelle Y. Liberman. In: S. A. Brady, D. P. Shankweiler (Eds.) Phonological Processes in Literacy. A Tribute to Isabelle Y. Liberman. Hillsdale (NJ): Lawrence Erlbaum, pp. xiii-Xvii.

Silva, F.; Viegas, F.; Duarte, I. M.; Veloso, J. (2011) Oral. Guião de Implementação do Programa de Português do Ensino Básico. Lisboa: Ministério da Educação/DGIDC.

Sim-Sim, I. (1989) Consciência linguística e nível de leitura: Que relação? Ou Ler ou não ler... Eis a questão. In. F. Sequeira, I. Sim-Sim (Eds.). Maturidade linguística e aprendizagem da leitura. Braga: Universidade do Minho (Instituto de Educação), vol. 1, pp. 339-350.

Sun, B.; Zhou, H.; Zhu B. (2013) Effects of English Phonological Awareness Training on Chinese Child EFL Learners' Literacy Development. Canadian Social Science 9(1), pp. 56-64.

Vellutino, F. R.; Scanlon, D. M. (1991) The Preeminence of Phonologically Based Skills in Learning to Read. In. S. A. Brady, D. P. Shankweiler (Eds.) Phonological Processes in Literacy. A Tribute to Isabelle Y. Liberman. Hillsdale (NJ): Lawrence Erlbaum, pp. 237-252.

Veloso, J. (2006) A fonética e a fonologia na nova Terminologia Linguística para os Ensinos Básico e Secundário. In. I. Duarte, O. Figueiredo (Eds.) Terminologia Linguística: das teorias às práticas. Porto: Faculdade de Letras da Universidade do Porto, pp. 115-127.

Veloso, J.; Rodrigues, A. S. (2002) A presença da fonética e da fonologia no ensino do Português (ensino básico e secundário): Algumas considerações preliminares. In. I. M Duarte et al. (Eds.) Actas do Encontro 
Comemorativo dos 25 Anos do Centro de Linguística da Universidade do Porto. Porto: Centro de Linguística da Universidade do Porto, vol. 1, pp. 231-246.

Viana, F. L. P. (1998) Da Linguagem Oral à Leitura. Construção e validação do Teste de Identificação de Competências Linguísticas. Dissertação de Doutoramento, Universidade do Minho.

Wagner, R. K.; Torgesen, J. K. (1987) The Nature of Phonological Processing and Its Causal Role in the Acquisition of Reading Skills. Psychological Bulletin 101(2), pp. 192-212.

Wood, C.; Terrell, C. (1998) Preschool Phonological Awareness and Subsequent Literacy Development. Educational Psychology 18(3), pp. 253-274.

Yopp, H. K.; Yopp, R. H. (2009) Phonological Awareness Is Child's Play!. Young Children 64(1), pp. 12-21. 